\title{
Prevalence and risk factors for sensorineural hearing loss: Western Sicily overview
}

\author{
Pietro Salvago • Enrico Martines · Francesco Martines
}

Received: 16 August 2012/Accepted: 22 January 2013/Published online: 10 February 2013

(C) Springer-Verlag Berlin Heidelberg 2013

\begin{abstract}
The objective of this work was to evaluate the prevalence of sensorineural hearing loss (SNHL) and distribution of the main risk factors associated to it focusing on their role in the development of deafness and their interaction. We performed a global audiological assessment (through TEOAE, tympanometry and ABR) in 508 infants at risk studying the main risk factors reported by Joint Committee on Infant Hearing (2007). Fifty-one infants $(10.03 \%)$ were diagnosed with SNHL (45 bilateral and 6 unilateral) with a mean hearing threshold of $87.39 \pm 28.25 \mathrm{~dB}$ HL; family history of hearing impairment (HI) and TORCH infections indicated independent significant risk factors $(P<0.00001$ and $P=0.024$, respectively). High SNHL percentages were evidenced also in NICU babies, due to the various pathologies and risk factors presented by these infants, and among newborns who suffered from hyperbilirubinemia (11.97 and $9.52 \%$, respectively). The mean degree of hearing loss for children with family history of $\mathrm{HI}$ ( $>100 \mathrm{~dB}$ HL) emphasizes the necessity of an early diagnosis to avoid the consequences of auditory deprivation. Craniofacial abnormalities and
\end{abstract}

P. Salvago - F. Martines

Sezione di Otorinolaringoiatria, Dipartimento di Biomedicina

Sperimentale e Neuroscienze Cliniche (BioNeC),

Università degli Studi di Palermo,

Via del Vespro, 129, 90127 Palermo, Italy

E. Martines

Sezione di Audiologia, Dipartimento di Biopatologia

e Biotecnologie Mediche e Forensi (Di.Bi.Me.F.),

Università degli Studi di Palermo,

Via del Vespro, 129, 90127 Palermo, Italy

F. Martines $(\bowtie)$

Via Autonomia Siciliana 70, 90143 Palermo, Italy

e-mail: francesco.martines@unipa.it;

francescomartines@hotmail.com syndromes associated to HI showed an important relationship $(P<0.00001)$ with conductive hearing loss. A progressive increase was evidenced in SNHL incidence as the number of risk factors rises (from 5.12 for 2 risk factors to $28.5 \%$ for 5 or more) with a significant difference among the groups $(P=0.049)$; multiple risk factors showed an additional cofactor for HL $\left(r^{2}=0.93\right)$. Considering the high SNHL prevalence $(10.03 \%)$ in infants at risk, this study highlights the necessity to implement a neonatal hearing screening program in Western Sicily.

Keywords Infants at risk - Neonatal hearing screening Sensorineural hearing loss · NICU infants

\section{Introduction}

Among congenital anomalies, sensorineural hearing loss (SNHL) represents a condition occurring in 1-2 infants every 1,000 births $[1,2]$, with a prevalence increasing from 10 - to 50-fold in certain higher risk populations (for example, NICU babies). Comparing SNHL incidence with that of other congenital pathologies routinely screened at birth like phenylketonuria (1:15,000 newborns) and hypothyroidism (1:4,500 newborns), permanent hearing loss appears more frequent. In comparison to children with normal hearing, those with hearing loss experience more difficulties developing verbal skills (learning vocabulary, grammar, word order and idiomatic expressions), language, learning and speech. Hearing impairment influences also cognitive and affective development of infants making consequences in their interpersonal relationships [3, 4].

Thus, it is necessary to promote a system of prevention to detect hearing impairment in the first months of life. This objective can be reached by implementing a neonatal 
audiological screening extended to the entire population or at least to infants at risk. Specifically, Joint Committee on Infant Hearing (JCIH) in the Position Statement of 2007 [5] reported risk factors associated with hearing loss (JCIH 2007), expanding those presented in older risk registries [6]. Although a family history of hearing loss (syndromic or non-syndromic), cranio-facial abnormalities, prenatal infections (TORCH), hyperbilirubinemia requiring exchange transfusion, and culture-positive sepsis were previously reported, other independent neonatal risk factors have been included. These risk factors include a need for ventilation, use of oxygen supplementation, respiratory failure, low Apgar scores, acidosis, use of ototoxic drugs including furosemide (especially with high serum creatinine levels), treatment for hypotension, patent ductus arteriosus ligation, hyponatremia, and noise [7-14]. Interaction among risk factors has been evidenced [12].

Despite a large diffusion of newborn hearing screening (NHS) in most parts of the developed world as an essential instrument of neonatal care, in Italy there is no stipulated modality to reach the objective of SNHL early detection in individual regions. So an early diagnosis is made possible only by the initiatives taken by hospitals that have activated local programs based on the collaboration of the single birth centers and the Audiology Sections. This reality leads to a high percentage of undiscovered permanent hearing loss $(\sim 30 \%)$ with a medical diagnosis made in $30-40 \%$ of cases after sixth month of age.

The main purpose of this study was to evaluate the prevalence of SNHL on infants at risk in Western Sicily; additional goals were to describe the distribution of risk factors associated with SNHL analyzing their role in the development of deafness and the effects of their interaction, underling the importance of a suitable and adequate hearing assessment especially for those populations at risk for permanent hearing impairment.

\section{Materials and methods}

This study was carried out by Department of Audiology, University of Palermo, examining all the infants, transferred from the eight births centers of Western Sicily for the presence of risk indicators associated with permanent congenital, delayed-onset, or progressive hearing loss from January 2010 to December 2011; the subject group consisted of 527 infants, 298 males and 229 females, ranging from 4 to 20 weeks of life at the moment of the first appointment. After ethical Committee approval, the study protocol was fully explained to patients or their guardians, and written informed consent was obtained from each patient. Out of 527 patients, 519 (98.48 \%) accepted to participate in this study but 11 infants were lost to follow- up monitoring. The final response rate was $96.39 \%$ corresponding to 508 infants. Through the discharge letter released by the birth centers and through a questionnaire answered by the parents, the following risk factors were researched, making a distinction between prenatal and perinatal risk factors ( $\mathrm{JCIH})$ : in the first group, family history of permanent childhood hearing impairment, consanguinity, pregnant maternal infection (TORCH) and drugs exposition during pregnancy; in the second group, premature birth (gestational age $\leq 37$ weeks), intensive care in excess of 5 days, respiratory distress (IRDS), hyperbilirubinemia requiring exchange transfusion, very low birth weight $(<1,500 \mathrm{~g}$, VLBW), cranio-facial abnormality (CFA) and syndromes associated to $\mathrm{HI}$, perinatal infections like sepsis and meningitis, ototoxic drugs administration (furosemide, dexamethasone, vancomycin, gentamycin and tobramycin), acidosis, hyponatremia, head trauma.

An experienced audiologist and otorhinolaryngologist examined the condition of the external auditory canal and tympanic membrane with otoscopy, and nose, throat, head and face in search of ear anomalies and syndromic features related to hearing impairment.

The audiologic assessment was performed by the same qualified bio-medical staff and consisted of ABR, TEOAE and tympanometry measurement. ABR measurements were recorded in a soundproof room; all children were in natural sleep or in calm conditions throughout the assessment. Both ears were sequentially tested. AMPLAID mk22 auditory evoked potentials system was used for testing the infants. After adequate preparation of skin, recording silver electrodes were attached to upper forehead (recording electrode), the ipsilateral mastoid process (reference electrode) and contralateral mastoid process (ground electrode). Thus, the Fpz-M1-M2 electrode montage was used for recording the ABR. The acoustic stimuli consisted of unfiltered full square wave pulses of $100 \mu$ s duration and with alternating polarity. The clicks were delivered monaurally by a hand held TDH-49 headphone, at a rate of $21 \mathrm{~s}^{-1}$. The analysis time was $15 \mathrm{~ms}$. The recording bandwidth for click threshold determination was 100-2,500 Hz. The electrode and interelectrode impedance were insured to be below 5 and $2 \mathrm{k} \Omega$, respectively. Each run consisted of summing the responses to 2,000 clicks. Click stimuli were presented starting at a level of $100 \mathrm{~dB}$ HL. With step sizes of $10 \mathrm{~dB}$, the level was decreased until no response was found. The response threshold was estimated by the lowest level at which a response was found. An infant was considered to have passed the ABR test if a replicable wave $\mathrm{V}$ response was present at $30 \mathrm{~dB} \mathrm{HL}$ in both ears, while SNHL was defined as elevated ABR response thresholds $(\geq 40 \mathrm{~dB})$ in one or both ears. Moreover, the absolute latencies and interpeak intervals as well 
as the response thresholds were analyzed. Experienced clinical specialists interpreted the ABR response waves. The response latencies in milliseconds were obtained by establishing the peak of the wave and reading out the digitally displayed time. From the latency intensity curves, the level of conductive hearing loss was estimated (increase of overall waves absolute latencies without interpeak intervals modification). This has been described in the literature as a valid method to identify a conductive hearing loss [15]. TEOAE and tympanometry measurement were used to confirm the diagnosis of conductive hearing loss when available. In particular, the first one was performed using the Otodynamics ILO 288 USB II system with the standard settings; the stimulus level was set to $84 \mathrm{~dB}$ SPL, a number of 260 averages was used. Tympanometry was performed with an Interacoustics AT $235 \mathrm{H}$ system using the standard settings and a $1-\mathrm{kHz}$ probe frequency and an air pressure range of -400 to $-100 \mathrm{mmH}_{2} \mathrm{O}$ with automatic recording.

The parents of an infant with suspicion of hearing impairment were informed of the results of the initial test and received recommendations to return for a follow-up evaluation after 3 weeks. Statistical analysis was conducted with Matlab ${ }^{\circledR}$ computer programme; $\chi^{2}$ test, odds ratio (OR) and/or exact test of Fisher test were used, following usual conditions of application. Significance was set at 0.05 .

\section{Result}

Between January 2010 and December 2011, 508 infants at risk, ranged from 4 to 20 weeks of life, were examined at our department. Of the newborns, 214 were female $(42.13 \%)$ and 294 were male $(57.87 \%)$ with a male: female ratio $=1.37$.

Audiologic evaluation revealed the presence of hearing loss in 97 children (56 males and 41 females) and identified CHL in 46 infants $(9.05 \%)$ and SNHL in 51 children corresponding to $10.03 \%$ of the study group (32 males and 19 females, with a male:female ratio $=1.68$ ). There is no statistically significant difference in prevalence of SNHL among sex $\left(\chi^{2}=0.55, P=0.45, \mathrm{OR}=1.25\right)$. Out of 51 SNHL infants, 45 subjects $(88.23 \%)$ were diagnosed with bilateral SNHL; a symmetric HL, defined by an inter-aural threshold difference $<30 \mathrm{~dB}$, was evidenced in the $91.11 \%$ corresponding to 41 cases $(80.39 \%$ of the total infants suffering from SNHL), while in the $8.89 \%$ corresponding to 4 cases, this SNHL was asymmetric (interaural threshold difference $\geq 30 \mathrm{~dB}$ ). Finally, 6 infants $(11.76 \%)$ were affected by unilateral SNHL, with a response threshold in the best hearing ear $\leq 40 \mathrm{~dB}$. Among the total ears suffering from SNHL, our study evidenced an hearing threshold mean value of $88.47 \pm 28.28 \mathrm{~dB} \mathrm{HL}$ (median $100 \mathrm{~dB} \mathrm{HL}$ ) for the left ears, of $86.4 \pm 28.48 \mathrm{~dB}$ $\mathrm{HL}$ (median $100 \mathrm{~dB} \mathrm{HL}$ ) for the right ears, of $87.39 \pm 28.25 \mathrm{~dB}$ HL (median $100 \mathrm{~dB}$ HL) for both ears without any difference between left and right ears $(t=0.35$, f.d. $=94, P=0.72)$.

Of the total infants, $264(51.96 \%)$ presented one risk factor, while $244(48.04 \%)$ were exposed to multiple risk factors; specifically, 156 cases $(30.71 \%)$ were showed 2 risk factors, 62 infants $(12.2 \%)$ had 3 risk factors, 19 children $(3.74 \%)$ were affected by 4 risk factors and finally only 7 newborns $(1.37 \%)$ showed 5 or more risk factors.

Prevalence of prenatal risk factors (143 subjects corresponding to $27.14 \%$ ) was lower than that of perinatal risk factors (385 infants corresponding to $75.78 \%$ ) with a perinatal:prenatal ratio $=2.69$ (Table 1).

In the first group, 57 infants $(39.86 \%)$ had a familiar history of HI, 46 newborns $(32.16 \%)$ suffered from TORCH infections and 47 infants $(32.86 \%)$ were exposed to drugs during pregnancy.

In the second group that includes risk factors occurring from birth to the 28th day of life, prematurity, intensive care in excess of 5 days and respiratory distress showed the highest prevalence, with 191 infants born preterm $(49.61 \%), 142$ admitted to NICU (36.88\%) and 139 that suffered from IRDS (36.1\%). Lower percentage concerned other risk factors like hyperbilirubinemia requiring phototherapy, found in 63 newborns (16.36\%), VLBW, that regarded 48 infants $(12.46 \%)$, syndromes associated with $\mathrm{HI}$ and cranio-facial anomalies (CFA) which affected 71 children $(18.44 \%)$. Finally, 30 infants $(7.79 \%)$ suffered from perinatal infections (like sepsis and meningitis) with the administration of ototoxic antibiotics in 27 newborns (7.01\%); only 2 cases with head trauma were found $(0.52 \%)$. Figure 1 shows the SNHL prevalence relative to each group.

The univariate analysis showed a statistically significant correlation between a familiar history of $\mathrm{HI}$ and SNHL $\left(\chi^{2}=32.98, P<0.00001\right.$, OR $\left.=5.85\right)$ with an SNHL prevalence respectively of 31.57 and $7.31 \%$ for infants with and without this risk factor. Moreover, our study evidenced an important difference $(t=3.63$, f.d. $=49$, $P=0.0007)$ from the comparison of mean hearing threshold of SNHL newborns with family history of HI ( $>100 \mathrm{~dB}$ HL) and SNHL newborns exposed to other risk factors (75.75 $\pm 28.58 \mathrm{~dB} \mathrm{HL})$.

TORCH agents was showed to be an important predictor of SNHL $\left(\chi^{2}=5.08, P=0.024\right.$, OR $\left.=2.49\right)$; infants that suffered from TORCH infections had greater SNHL prevalence when compared to children with other risk factors (19.56 vs. $9.09 \%$ ). Of the 9 SNHL newborns positive to TORCH agents, $5(55.55 \%)$ were affected by cytomegalovirus (CMV) infection. 
Table 1 Distribution, Chi-square, odds ratio, $95 \% \mathrm{CI}$ and hearing threshold mean values relative to prenatal and perinatal risk factors of total infants

\begin{tabular}{|c|c|c|c|c|c|c|c|}
\hline Risk factor & $\begin{array}{l}\text { No. of infant (508) } \\
N(\%)\end{array}$ & $\begin{array}{l}\text { SNHL (51) No./total } \\
\text { group (\%) }\end{array}$ & $\chi^{2}$ & $P$ & OR & $95 \% \mathrm{CI}$ & $\begin{array}{l}\text { Mean hearing threshold } \\
\text { (dB HL) }\end{array}$ \\
\hline \multicolumn{8}{|l|}{ Prenatal } \\
\hline Family history of HI & $57(11.2)$ & $18(35.29)$ & 32.98 & $<0.00001$ & 5.85 & $3.02-11.33$ & $>100$ \\
\hline TORCH & $46(9.05)$ & $9(17.64)$ & 5.08 & 0.024 & 2.49 & $1.10-5.38$ & 67.2 \\
\hline $\begin{array}{l}\text { Drugs administration in } \\
\text { pregnancy }\end{array}$ & $47(9.25)$ & $1(9.26)$ & & 0.71 & & & 50 \\
\hline \multicolumn{8}{|l|}{ Perinatal } \\
\hline Prematurity & $191(37.59)$ & $11(21.56)$ & 6.21 & 0.0127 & 0.42 & $0.21-0.85$ & 75.54 \\
\hline NICU & $142(27.95)$ & $17(33.33)$ & 0.81 & 0.36 & 1.33 & $0.72-2.46$ & 79.41 \\
\hline IRDS & $139(27.36)$ & $10(19.6)$ & 1.71 & 0.19 & 0.62 & $0.3-1.27$ & 89 \\
\hline Hyperbilirubinemia & $63(12.4)$ & $6(11.76)$ & 0.02 & 0.88 & 0.94 & $0.38-2.29$ & 72.5 \\
\hline VLBW & $48(9.44)$ & $4(7.84)$ & & 1 & & & 90 \\
\hline $\begin{array}{l}\text { CFA and syndromes } \\
\text { associated to } \mathrm{HI}\end{array}$ & $71(13.97)$ & $5(9.8)$ & 0.82 & 0.36 & 0.64 & $0.25-1.68$ & 72 \\
\hline Perinatal infections & $30(5.9)$ & $1(1.96)$ & & 0.344 & & & $>100$ \\
\hline Ototoxic drugs & $27(5.31)$ & $3(5.88)$ & & 0.745 & & & $>100$ \\
\hline Head trauma & $2(0.39)$ & $0(0)$ & & & & & I \\
\hline
\end{tabular}

IRDS respiratory distress, $V L B W$ very low birth weight, $C F A$ cranio-facial abnormality

Fig. 1 Prevalence of SNHL for single prenatal and perinatal risk factor

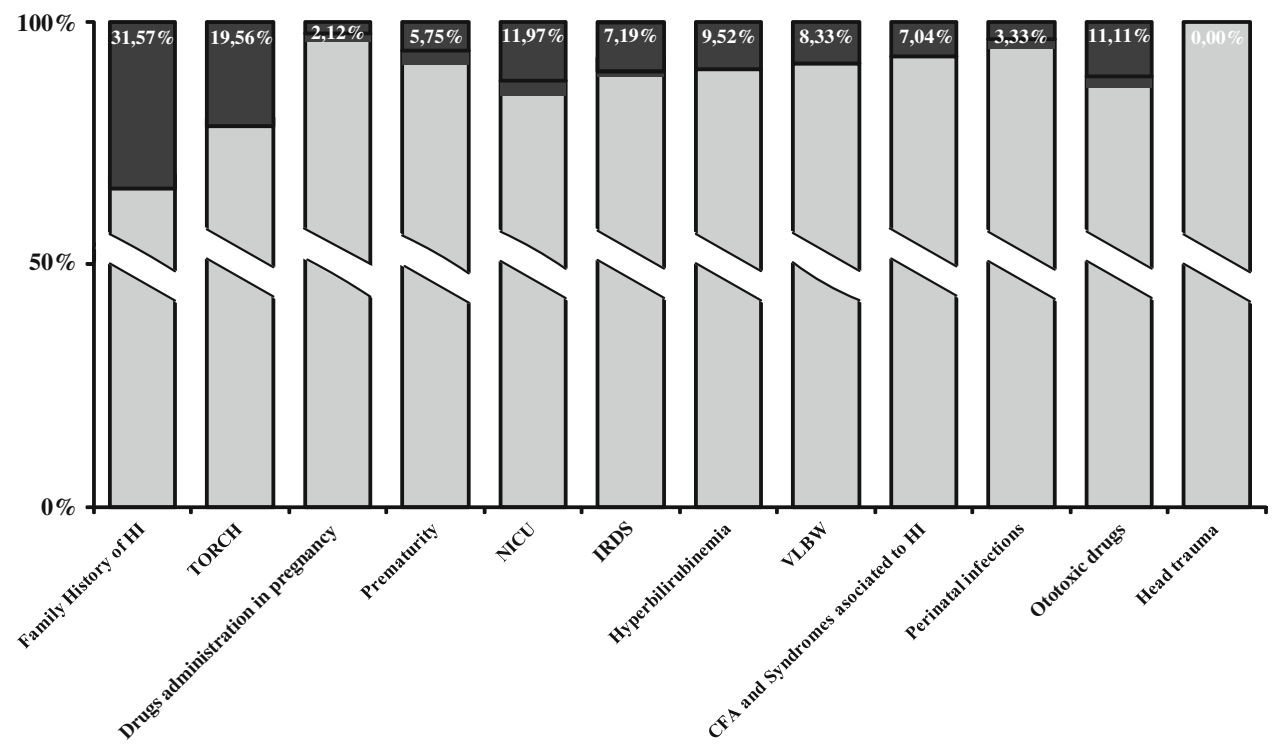

SNHL $\square$ NHL
Drugs administration in pregnancy demonstrated no statistically significant influence on SNHL; indeed of the 47 children presenting this risk factor, only one infant $(2.12 \%)$ developed SNHL.

The role of prematurity as risk factor for SNHL was also assessed; children who were preterm had a lower SNHL rates when compared to those exposed to other risk factors $(5.75$ vs. $12.61 \%)$, with a statistically significant difference $\left(\chi^{2}=6.21, P=0.012\right)$. The mean gestational age study between NHL and SNHL preterm infants showed no significant differences among the subjects (mean weeks $=33.2 \pm 3.1$ for NHL and $32.2 \pm 4.5$ for SNHL infants with $t=1.039, P=0.299$ ), even if with $P=0.045$ statistical analysis revealed a higher percentage of SNHL in children born before the 30th week than those preterm who born after 30th week.

Nevertheless, a high prevalence of SNHL among NICU babies $(11.97 \%)$, we did not find any difference between newborns admitted to NICU for more than 5 days and those exposed to other risk factors. An infant staying alive 
in NICU has a $33 \%$ greater chance of developing SNHL compared with others newborns, but the relation is not statistically significant $\left(\chi^{2}=0.81, P=0.36, \mathrm{OR}=1.33\right)$. A detailed analysis of characteristics of NICU newborns is shown in Table 2.

According to Table 1, among infants that suffered from IRDS and hyperbilirubinemia, we evidenced an incidence of SNHL of $7.19 \%\left(\chi^{2}=1.71, P=0.19\right.$, OR $\left.=0.62\right)$ and $9.52 \%$, respectively $\left(\chi^{2}=0.02, P=0.88\right.$, OR $\left.=0.84\right)$; furthermore, there is no difference between newborns with VLBW and those without $(P=1)$. Among SNHL children with VLBW (4/48 corresponding to $8.33 \%$ of the group), a significant difference was evidenced between infants who had a birth weight $<1,000 \mathrm{~g}$ ( 3 cases of 4 with SNHL) and those who weighed $\geq 1,000 \mathrm{~g}$ ( $P=0.017)$; furthermore, the mean weight calculated for SNHL infants was $950 \pm 40.82 \mathrm{~g}$ instead of $1,193.04 \pm 236.94 \mathrm{~g}$ for $\mathrm{NHL}$ newborns $(t=2.02$, f.d. $=46, P=0.048)$.

CFA and syndromes associated to HI were studied and no statistically significant relationship with SNHL was found $\left(\chi^{2}=0.82, P=0.36, \mathrm{OR}=0.64\right)$. However, we evidenced higher percentage of CHL (54.34\%) in newborns that presented CFA or syndromes associated with SNHL $\left(\chi^{2}=68.57, P<0.00001\right)$.

Finally, a prevalence of SNHL of 3.33, 11.11 and $0 \%$ was found in newborns with perinatal infections, administration of ototoxic antibiotics and head trauma, respectively. No statistically significant relationship with SNHL was found.

The analysis of the auditory deficit for infants presenting two or more risk factors showed significant statistical difference in prevalence of SNHL among the groups $\left(\chi^{2}=7.84, P=0.049\right.$, fd $\left.=3\right)$. In fact, we evidenced an incidence of SNHL of $5.12 \%(\mathrm{OR}=0.61)$ in newborns with two audiological risk factors, of $7.69 \%(\mathrm{OR}=1.09)$ for three risk factors, of $15.78 \%(\mathrm{OR}=2.56)$ for four risk factors and of $28.5 \%(\mathrm{OR}=5.44)$ in case of five or more risk factors (mean hearing threshold values of $76.25 \pm$ $28.5 \mathrm{~dB}$ HL, $72.5 \pm 33.04 \mathrm{~dB}$ HL, $96.66 \pm 40.41 \mathrm{~dB}$ HL, $85 \pm 49.49 \mathrm{~dB}$ HL, respectively). The study of mean hearing threshold for each risk factor is reported in Table 1.

\section{Discussion}

Actually, in Italy, the absence of a unique stipulated modality for an early detection of HI (extended to the entire country) makes more ineffective the identification of deafness in the early childhood with a certain number of SNHL remaining undiscovered or diagnosed after 6th month of age. In fact, the NHS coverage percentage ranges from $79.5 \%$ for the North-West Italy, corresponding to the most economically developed areas, to $11.3 \%$ for the Islands like Sicily where the initiatives are still left to individual hospitals (often without qualified instrumentation and specialized medical staff) [16-18].

The aim of our report was to study, through a global audiologic evaluation, the SNHL prevalence and the distribution of the main risk factors for permanent congenital, delayed-onset, or progressive hearing loss (identified by JCIH 2007) and their correlation with SNHL, among a cohort of 508 infants at risk, who were transferred to the only tertiary Speech and Hearing Center of Western Sicily, from all the birth centers that decided to participate in the study from January 2010 to December 2011.

In fact, according to literature, the identification inside a population of the cause of the hearing loss provides new information relevant to hearing loss management,

Table 2 Analysis of risk factors for SNHL among NICU newborns: logistic regression analysis, correlation coefficient $b, P$ value, odds ratio and $95 \%$ confidence limits

\begin{tabular}{llllc}
\hline Risk factor & $\begin{array}{l}\text { NHL (125) } \\
N(\%)\end{array}$ & $\begin{array}{l}\text { SNHL }(17) \\
N(\%)\end{array}$ & $\begin{array}{l}\text { Odds ratio (OR, partial logistic regression } \\
\text { coefficient } b)\end{array}$ & $P$ value \\
\hline Family history of HI & $1(0.8)$ & $1(5.88)$ & $7.75(2.04)$ & 0.15 \\
TORCH & $3(2.4)$ & $2(11.76)$ & $5.42(1.69)$ & $0.46-130.06$ \\
Drugs administration in & $8(6.4)$ & $1(5.88)$ & $0.805(-0.21)$ & 0.076 \\
$\quad$ pregnancy & & & $0.837-35.1$ \\
Prematurity & $36(28.8)$ & $7(41.17)$ & $2.03(0.71)$ & $0.09-6.78$ \\
IRDS & $60(48)$ & $10(58.82)$ & $2.07(0.72)$ & 0.018 \\
Hyperbilirubinemia & $19(15.2)$ & $6(35.29)$ & $3.58(1.27)$ & $0.71-5.79$ \\
VLBW & $24(19.2)$ & $4(23.52)$ & $1.29(0.25)$ & 0.16 \\
Perinatal infections & $17(13.6)$ & $1(5.88)$ & $0.58(-0.53)$ & $0.74-5.8$ \\
Ototoxic drugs & $18(14.4)$ & $2(11.76)$ & $0.53(-0.61)$ & 0.035 \\
CFA and syndromes associated & $11(8.8)$ & $0(0)$ & $/$ & $0.09-11.81$ \\
$\quad$ to HI & & & $0.38-4.32$ \\
\hline
\end{tabular}

IRDS Respiratory distress, $V L B W$ very low birth weight, $C F A$ cranio-facial abnormality 
coexisting medical problems, and the prognosis for the child and family. In addition, our study could clarify the epidemiological features of congenital deafness, facilitating the planning of effective hearing loss prevention and future surveillance programs in Sicily.

Using as criteria of inclusion the presence of hearing threshold $\geq 40 \mathrm{~dB}$ HL in at least one ear, 51 subjects (10.03\% of the total infants studied) were identified with SNHL; our study showed a higher SNHL percentage when compared with those reported by Ohl et al. (4.55\%), Meyer et al. (5.3\%), Robertson et al. (3.1\%) and Elahi et al. (7.9\%) [19-22]. The variability in incidence of SNHL is explicable analyzing the heterogeneous distribution of risk factors among the cohort studied and the criteria (like hearing threshold) applied to make diagnosis of SNHL. Specifically, our incidence value is higher because a large percentage of infants included in the study has a family history of SNHL. In fact, in our cohort, the SNHL prevalence was $7.31 \%$ (33/451) excluding 'family history of HI' group, while it was $6.27 \%(28 / 446)$ and $5.85 \%$ in case of bilateral SNHL and in case of bilateral SNHL with hearing threshold $\geq 50 \mathrm{~dB}$ HL for the best ear, respectively.

The study of distribution of risk factors among Western Sicily cohort evidenced, as stated above, a high incidence $(57 / 508,11.22 \%)$ of a family history of HI, probably due to the great number of marriages between consanguineous occurring in the past years [23]. Of them, $18(31.57 \%)$ presented SNHL $\left(\chi^{2}=32.98, P<0.00001\right)$, with a mean hearing threshold of $>100 \mathrm{~dB}$ HL (in the $77.77 \%$ of cases, the hearing loss was profound). This little variability in degree of SNHL revealed by our report may appear to be markedly in contrast with that reported by Picciotti et al. [24] but, as explained by these authors, the variable phenotype should be attributed to ethnic diversity in expression of the gene associated with SNHL, to the presence of coexisting mutations regarding different genes correlated with SNHL and to the influence of environmental factors. However, analyzing the degree of hearing loss of cases belonging to the Southern Italy and with a family history of HI, we observed, in line with our results, a mean hearing threshold of $102.81 \pm 21.27$.

The preeminent role of family history in the development of deafness was hypothesized by Meyer et al. [20], who also defined this condition as independent risk factor; it was subsequently underlined by Fortnum [1] and Jakubíková et al. [25], and supported by our findings $(P<0.00001, \mathrm{OR}=5.85)$.

Another statistically significant prenatal risk factors revealed by our analysis were TORCH agents; although with 46/508 cases TORCH infections are little represented in our cohort, probably due to good systems of prevention like rubella vaccine, they are strongly associated with SNHL $\left(\chi^{2}=5.08, P=0.024, \mathrm{OR}=2.49\right)$; according to literature data [5, 25-27], even our study empathizes the role of CMV among TORCH agents and in the development of SNHL. Particularly, of the 46 newborns suffering from TORCH infections, $25(54.34 \%)$ were positive to CMV, 8 to Rubella (17.39\%) and $13(28.26 \%)$ to Toxoplasmosis; moreover, even if a significant difference among the subgroups $\left(\chi^{2}=2.8, P=0.246\right.$, f.d. $\left.=2\right)$ was not found, with a percentage value of $55.55 \%$ of SNHL infants (corresponding to 5/9 subjects), the CMV infection was the main cause of deafness among TORCH agents, while in 3 cases $(33.33 \%)$, the Rubella cause was evidenced and in only 1 infant (11.11\%), Toxoplasmosis was diagnosed. Considering SNHL infants positive to CMV infections, our study revealed an hearing loss from moderate to profound, with a mean hearing threshold of $76 \pm 20.43 \mathrm{~dB}$ HL, not very different than those reported by Madden et al. [28] and Mussi-Pinhata et al. [29].

Literature data report that more than $30 \%$ of infants with SNHL were recovered in NICU [30-35]. In $33.33 \%$ (17/51) of infants with this risk factor among SNHL newborns, even our report shows that NICU increases slightly the probability to be hearing impaired $(\mathrm{OR}=1.33)$. It is also evidenced by ANOVA test (Fig. 2). With a prevalence rate of $11.97 \%$ of SNHL NICU babies, our percentage is higher than those reported by Coenrad et al. (1.39\%), Hille et al. (3.1\%) and Robertson et al. $(3.2 \%)$ and inferior to those evidenced by Davis and Parving (32.8\%), Shiu et al. (30.9\%) and Pitt (32 \%) [14, 21, 31, 33, 35, 36]. According to Dauman et al. [37], the high variability in incidence of SNHL among newborns admitted to NICU reflects a heterogeneous distribution of different neonatal risk factors more or less involved in the development of SNHL. In addition, another consideration should be made for NICU babies: these newborns, in fact, present often multiple risk factors, a condition that increases the probability of hearing impairment. Table 2 reports logistic regression analysis for each risk factors in our NICU cohort; results of a simultaneous multiple regression analysis of the variation in SNHL prevalence among NICU infants demonstrated that the relative risk for SNHL increases by $21.24 \%$ in preterm infants and by $19.33 \%$ in newborns who suffered from hyperbilirubinemia when respiratory distress is concomitant with these risk factors. Furthermore, in this cohort, we observed a higher risk of SNHL $(99.66 \%)$ in case of coexistence of prematurity and hyperbilirubinemia.

Our study also underlined the role of gestational age and birth weight as risk factors for SNHL; specifically, among the 191 preterm infants, $29(15.18 \%)$ presented extreme prematurity and of them 4 (corresponding to $13.79 \%$ subjects) were hearing impaired $(P=0.045)$. Among newborns with very low birth weight, a statistically difference was evidenced between infants with weight $<1,000 \mathrm{~g}$ and 


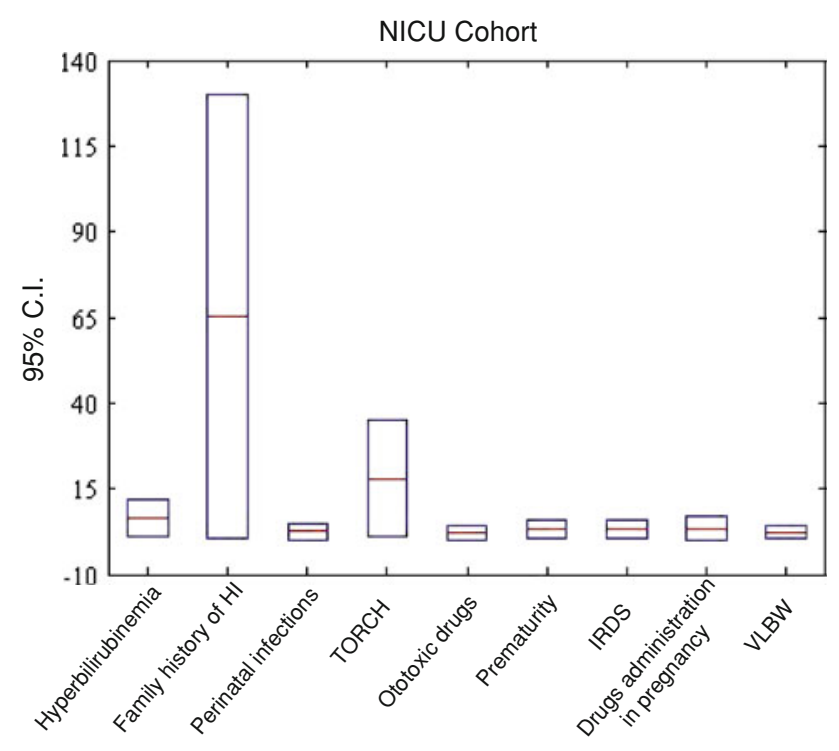

Fig. 2 NICU cohort: $95 \%$ CI (ANOVA test) for single risk factor

those who weighed at birth $\geq 1,000 \mathrm{~g}$; in fact, the SNHL prevalence percentages inside the groups resulted in 8.33, 2.56 and $33.33 \%$ for the total infants with VLBW, for newborns weighed between 1,000 and $1,500 \mathrm{~g}$ and for children with extremely low birth weight $(<1,000 \mathrm{~g})$, respectively $(P=0.017)$. These findings are explainable considering that the greater the severity of prematurity and the lower the birth weight, more probable is the coexistence of condition like severe birth asphyxia or assisted ventilation for $\geq 5$ days that increase the risk of SNHL [12, 38].

The association of two or more risk factors, found in $48.03 \%$ of our infants cohort, also appeared to be an additional risk for SNHL. As reported by Ohl et al. [19] and Bielecki et al. [39], our study evidenced a progressive increase in prevalence of SNHL as the number of risk factors rose; in fact, in children with two to six coexisting risk factors the probability of SNHL ranges from 5.16 to $28.5 \%\left(r^{2}=0.93\right)$.

Finally, concerning the group with CFA and syndromes associated with HI, as shown in Table 1, no difference was evidenced between SNHL and the NHL infants, whereas the same subjects were shown to be more susceptible to develop CHL $\left(\chi^{2}=68.57, P<0.00001\right)$. It is explainable considering that most of the 71 infants presented cleft palate $(16.9 \%)$ or Down syndrome $(38.02 \%)$, two conditions often associated with middle ear effusion, upper airway infections with consequent CHL [40-43].

\section{Conclusion}

This report shows that $10.03 \%$ of infants at risk in Western Sicily suffer from SNHL; with a mean hearing threshold of
$87.39 \pm 28.25 \mathrm{~dB}$ HL (median $100 \mathrm{~dB}$ HL), it underlines the necessity of an early diagnosis before the 6th month of life to prevent sequelae and complications such as irreversible delay in speech and cognitive development. According to data literature, among prenatal risk factors (JCIH 2007), family history of HI and TORCH agents (especially CMV infections) indicated independent risk factors $(P<0.00001$ and $P=0.024)$. NICU infants have a $33 \%$ greater chance of developing SNHL, because of the presence of multiple risk factors $(\mathrm{OR}=1.33)$; in fact, as the number of coexisting risk factors increases, the prevalence of SNHL also increases $\left(r^{2}=0.93\right)$.

Conflict of interest The authors declare that they have no conflict of interest.

\section{References}

1. Fortnum HM (2003) Epidemiology of permanent childhood hearing impairment: implication for neonatal hearing screening. Audiol Med 1:155-164

2. Declau F, Boudewyns A, Van den Ende J, Peeters A, van den Heyning P (2008) Etiologic and audiologic evaluations after universal neonatal hearing screening: analysis of 170 referred neonates. Pediatrics 121:1119-1126

3. Yoshinaga-Itano C, Coulter D, Thomson V (2000) The Colorado Newborn Hearing Screening Project: effects on speech and language development for children with hearing loss. J Perinatol 20:S132-S137

4. Moeller MP (2000) Early intervention and language development in children who are deaf and hard of hearing. Pediatrics 106:E43

5. American Academy of Pediatrics (2007) Joint Committee on Infant Hearing. Year 2007 position statement: principles and guidelines for early hearing detection and intervention programs. Pediatrics 120:898-921

6. American academy of Pediatrics (1982) Joint Committee on Infant Hearing. Position Statement 1982. Pediatrics 70:496-497

7. Nield TA, Schreir S, Ramos AD, Platzker D, Warburton ACG (1986) Unexpected hearing loss in high-risk infants. Pediatrics 78:417-422

8. Salamy A, Eldredge L, Tooley WH (1989) Neonatal status and hearing loss in high-risk infants. J Pediatr 114:847-852

9. Borradori C, Fawer CL, Baclin T, Calame A (1997) Risk factors of sensorineural hearing loss in preterm infants. Biol Neonate $71: 1-10$

10. Borg E (1997) Perinatal asphyxia, hypoxia, ischemia, and hearing loss: an overview. Scand Audiol 26:77-91

11. American Academy of Pediatrics, Committee on Environmental Health (1997) Noise: a hazard for the fetus and newborn. Pediatrics 100:724-727

12. Marlow ES, Hunt LP, Marlow N (2000) Sensorineural hearing loss and prematurity. Arch Dis Child Fetal Neonatal 82:F141F144

13. Fanaroff JM, Wilson-Costell DE, Newman NS, Montpetite MM, Fanaroff AA (2006) Treated hypotension is associated with neonatal morbidity and hearing loss in extremely low birth weight infants. Pediatrics 117:1131-1135

14. Hille ETM, van Straaten HLM, Verlerk PH (2007) Dutch NICU Neonatal Hearing Screening Working Group. Prevalence and independent risk factors for hearing loss in NICU infants. Acta Paediatr 96:1155-1158 
15. Vander Werff KR, Prieve BA, Georgantas LM (2009) Infant air and bone conduction tone burst auditory brain stem responses for classification of hearing loss and the relationship to behavioral thresholds. Ear Hear 30:350-368

16. Martines F, Porrello M, Ferrara M, Martines M, Martines E (2007) Newborn hearing screening project using transient evoked otoacoustic emissions: Western Sicily experience. Int J Pediatr Otorhinolaryngol 71:107-112

17. Martines F, Bentivegna D, Ciprì S, Costantino C, Marchese D, Martines E (2012) On the threshold of effective well infant nursery hearing screening in Western Sicily. Int $\mathrm{J}$ Pediatr Otorhinolaryngol 76:423-427

18. Martines F, Salvago P, Bentivegna D, Bartolone A, Dispenza F, Martines E (2012) Audiologic profile of infants at risk: experience of a Western Sicily tertiary care centre. Int $\mathrm{J}$ Pediatr Otorhinolaryngol 76:1285-1291

19. Ohl C, Dornier L, Czajka C, Chobaut JC, Tavernier L (2009) Newborn hearing screening on infants at risk. Int $\mathrm{J}$ Pediatr Otorhinolaryngol 73:1691-1695

20. Meyer C, Witte J, Hildmann A, Hennecke KH, Schunck KU, Maul K, Franke U, Fahnenstich H, Rabe H, Rossi R, Hartmann S, Gortner L (1999) Neonatal screening for hearing disorders in infants at risk: incidence, risk factors, and follow-up. Pediatrics 104:900-904

21. Robertson CM, Howarth TM, Bork DL, Dinu IA (2009) Permanent bilateral sensory and neural hearing loss of children after neonatal intensive care because of extreme prematurity: a thirtyyear study. Pediatrics 123:e797-e807

22. Elahi MM, Elahi F, Elahi A, Elahi SB (1998) Paediatric hearing loss in rural Pakistan. J Otolaryngol 27:348-353

23. Martines E, Amodeo AM, Grisanti S, Martines F (2000) Sordità ereditaria recessiva nella Sicilia occidentale: studio epidemiologico su tre coorti. Acta Medica Mediterranea 16:19-22

24. Picciotti PM, Pietrobono R, Neri G, Paludetti G, Fetoni AR, Cianfrone F, Pomponi MG (2009) Correlation between GJB2 mutations and audiological deficits: personal experience. Eur Arch Otorhinolaryngol 266:489-494

25. Jakubíková J, Kabátová Z, Pavlovcinová G, Profant M (2009) Newborn hearing screening and strategy for early detection of hearing loss in infants. Int J Pediatr Otorhinolaryngol 73:607-612

26. Grosse SD, Ross DS, Dollard SC (2008) Congenital cytomegalovirus (CMV) infection as a cause of permanent bilateral hearing loss: a quantitative assessment. J Clin Virol 41:57-62

27. Barbi M, Binda S, Caroppo S, Primache V (2006) Neonatal screening for congenital cytomegalovirus infection and hearing loss. J Clin Virol 35:206-209

28. Madden C, Wiley S, Schleiss M, Benton C, Meinzen-Derr J, Greinwald J, Choo D (2005) Audiometric, clinical and educational outcomes in a pediatric symptomatic congenital cytomegalovirus (CMV) population with sensorineural hearing loss. Int $\mathbf{J}$ Pediatr Otorhinolaryngol 69:1191-1198
29. Mussi-Pinhata MM, Yamamoto AY, Moura Brito RM, de Lima Isaac M, de Carvalho e Oliveira PF, Boppana S, Britt WJ (2009) Birth prevalence and natural history of congenital cytomegalovirus infection in a highly seroimmune population. Clin Infect Dis 49:522-528

30. Van Naarden K, Decouflé P, Caldwell K (1999) Prevalence and characteristics of children with serious hearing impairment in metropolitan Atlanta, 1991-1993. Pediatrics 103:570-575

31. Davis AC, Parving A (1993) Towards appropriate epidemiological data on childhood hearing disability: a comparative European study of birth cohorts. J Audiol Med 3:35-47

32. Sutton GJ, Rowe SJ (1997) Risk factors for childhood sensorineural hearing loss in the Oxford region. Br J Audiol 31:39-54

33. Shiu J, Purvis M, Sutton G (1996) Detection of childhood hearing impairment in the Oxford Region. Report of the Regional audit project. Oxfordshire RHA, Oxford

34. Fortnum H, Davis A (1997) Epidemiology of permanent childhood hearing impairment in Trent Region, 1985-1993. Br J Audiol 31:409-446

35. Pitt T (1995) Management and outcome: children fitted with hearing aids in Ireland. Br J Audiol 29:199-207

36. Coenraad S, Goedegebure A, Hoeve LJ (2011) An initial overestimation of sensorineural hearing loss in NICU infants after failure on neonatal hearing screening. Int J Pediatr Otorhinolaryngol 75:159-162

37. Dauman R, Roussey M, Belot V, Denoyelle F, Roman S, Gavilan-Cellié I (2009) Screening to detect permanent childhood hearing impairment in neonates transferred from the newborn nursery. Int J Pediatr Otorhinolaryngol 73:457-465

38. Leslie GI, Kalaw MB, Bowen JR, Arnold JD (1995) Risk factors for sensorineural hearing loss in extremely premature infants. J Paediatr Child Health 31:312-316

39. Bielecki I, Horbulewicz A, Wolan T (2011) Risk factors associated with hearing loss in infants: an analysis of 5282 referred neonates. Int J Pediatr Otorhinolaryngol 75:925-930

40. Kwan WM, Abdullah VJ, Liu K, van Hasselt CA, Tong MC (2011) Otitis media with effusion and hearing loss in chinese children with cleft lip and palate. Cleft Palate Craniofac J 48:684-689

41. Sheahan P, Miller I, Sheahan JN, Earley MJ, Blayney AW (2003) Incidence and outcome of middle ear disease in cleft lip and/or cleft palate. Int J Pediatr Otorhinolaryngol 67:785-793

42. Park AH, Wilson MA, Stevens PT, Harward R, Hohler N (2012) Identification of hearing loss in pediatric patients with Down syndrome. Otolaryngol Head Neck Surg 146:135-140

43. McPherson B, Lai SP, Leung KK, Ng IH (2007) Hearing loss in Chinese school children with Down syndrome. Int J Pediatr Otorhinolaryngol 71:1905-1915 